Published in final edited form as:

Addiction. 2015 May ; 110(5): 775-783. doi:10.1111/add.12881.

\title{
Personality, negative affect coping, and drinking alone: a structural equation modeling approach to examine correlates of adolescent solitary drinking
}

\author{
Kasey G. Creswell ${ }^{1}$, Tammy Chung $^{2}$, Aidan G. C. Wright ${ }^{2,3}$, Duncan B. Clark ${ }^{2}$, Jessica J. \\ Black $^{2}$, and Christopher S. Martin² \\ ${ }^{1}$ Department of Psychology, Carnegie Mellon University, Pittsburgh, PA, USA \\ ${ }^{2}$ Department of Psychiatry, University of Pittsburgh, Pittsburgh, PA, USA \\ ${ }^{3}$ Department of Psychology, University of Pittsburgh, Pittsburgh, PA
}

\section{Abstract}

\begin{abstract}
Aims-This study examined the personality traits of negative emotionality and constraint and the ability to resist drinking during negative affective states as correlates of solitary drinking in adolescence. We hypothesized that higher levels of negative emotionality and lower levels of constraint would predict solitary drinking and that these relationships would be mediated by the ability to resist drinking in response to negative emotions.
\end{abstract}

Design-Structural equation modeling was used to fit a path model from the personality traits of negative emotionality and constraint to solitary drinking status through intermediate effects on the ability to resist drinking during negative emotions using cross-sectional data.

Setting-Clinical and community settings in Pennsylvania, USA.

Participants-The sample included 761 adolescent drinkers (mean age $=17.1)$.

Measurements-Adolescents completed the Lifetime Drinking History, the Multidimensional Personality Questionnaire, the Constructive Thinking Inventory and the Situational Confidence Questionnaire.

Findings-The path model provided a good fit to the data. The association between trait negative emotionality and solitary drinking was fully mediated by adolescents' ability to resist drinking during negative affective states $(b=0.05, P=0.01)$. In contrast, constraint had a direct effect on solitary drinking (odds ratio $(\mathrm{OR})=0.79, b=-0.23, \mathrm{P}<0.01$ ), as well as an indirect effect through the ability to resist drinking during negative affective states $(b=-0.03, P=0.02)$.

\footnotetext{
(C) 2015 Society for the Study of Addiction

Correspondence to: Kasey Creswell, Assistant Professor in Psychology, Carnegie Mellon University, 5000 Forbes Avenue, Pittsburgh, PA 15213, USA. kasey@andrew.cmu.edu.

Declaration of interests

None.

Supporting information

Additional supporting information may be found in the online version of this article at the publisher's web-site:
} 
Conclusions-The ability to resist drinking while experiencing negative feelings or emotions may be an important underlying mechanism linking trait negative emotionality (a tendency toward depression, anxiety and poor reaction to stress) and constraint (lack of impulsiveness) to adolescent solitary drinking.

\section{Keywords}

Adolescents; alcohol; drinking context; personality; social context; solitary drinking; solitary use

\section{INTRODUCTION}

Alcohol use becomes increasingly prevalent across adolescence [1,2], but context is important when determining normative drinking behavior for this age group [3]. Adolescent drinking usually occurs with friends [1]. Such socially driven alcohol use has been considered by some researchers to be a normative aspect of psychosocial development, representing a marker for popularity, adjustment and how well-socialized adolescents are into their peer groups [3-6]. Among adults, solitary drinking (i.e. drinking while alone) is relatively common and is not in itself a risk factor for alcohol-related problems [7-9]. Solitary drinking during adolescence, however, is considered deviant. For example, in the Monitoring the Future Study, 94\% of high school seniors reported that they either never drank alone or had done so just a few times [10].

Importantly, compared to teens who only drink socially, teen solitary drinkers have higher rates of alcohol problems in cross-sectional studies, and prospective studies show that they are significantly more likely to develop alcohol problems in young adulthood (even after controlling for alcohol quantity/frequency) $[11,12]$. For instance, in a large study of adolescents recruited from community and clinical settings, Creswell et al. [11] showed that teen solitary drinkers had heavier and more frequent alcohol use, met criteria for more alcohol use disorder (AUD) symptoms, were younger the first time they experienced alcohol intoxication and were more likely to endorse heavy drinking during negative affect. Furthermore, teen solitary drinking predicted alcohol problems in young adulthood even after accounting for other established AUD risk factors such as drinking quantity/frequency and prior AUD symptoms [11]. Because solitary drinking in adolescence is associated with alcohol problems in young adulthood above and beyond other established risk factors for alcohol problems [11,12], it is important to understand the mechanisms underlying this risky behavior. The limited existing literature suggests that adolescent solitary drinking is associated with trait negative emotionality and coping responses, particularly drinking to cope with negative affect, but no study has specified or tested a model that links personality traits with adolescent solitary drinking through coping responses.

Trait negative emotionality has been linked to increased risk for alcohol problems [13-18]. To predict solitary drinking, cross-sectional studies have focused on negative affect and depression symptoms. For example, negative affect/depression has been associated with solitary drinking among college students $[19,20]$ and adolescents $[3,11,21]$. Further, solitary drinking teens reported using alcohol to alleviate or cope with negative affect [12,22], a pattern of use that may place them at high risk to escalate alcohol involvement $[23,24]$. A 
prospective daily diary study of alcohol consumption in an adult community sample (mean age $=33.9, \mathrm{SD}=4.6$ ) found that individuals engaged in more solitary drinking on days when they experienced more negative interpersonal experiences, an effect that was particularly strong for individuals high on neuroticism [25]. Taken together, prior studies have reported associations between negative emotionality, drinking to cope with negative affect and solitary drinking, but they have not determined whether drinking to cope mediates the association between negative emotionality and solitary drinking.

Drinking to cope is thought to represent a more proximal predictor of drinking behavior through which personality traits such as negative emotionality may operate [26-29]. Further, a model demonstrating that drinking to cope mediates the relationship between negative affect and solitary drinking would provide support for the self-medication hypothesis of solitary alcohol use. This model proposes that solitary drinkers use alcohol to cope with negative affect $[11,21]$. To our knowledge, this study is the first to test a pathway from negative emotionality to solitary drinking through intermediary effects on drinking to cope.

In addition to negative emotionality, another personality trait that has been consistently linked to alcohol problems is impulsivity, or lack of constraint $[13,16,18,29,30]$. No prior study has examined the relationship between the personality trait of impulsivity/lack of constraint and solitary drinking. However, one study [12] found that 8th grade solitary drinkers were more likely to engage in deviant behavior (e.g. stealing). To the extent that these externalizing behaviors tap into trait impulsivity/lack of constraint [16,29,31], then it is plausible that adolescents who engage in solitary drinking may do so because of difficulties in controlling their behavior. In addition, accounting for impulsivity or lack of constraint might mitigate the relationship between negative emotionality and solitary drinking. This study is also the first to determine the relative importance of trait negative emotionality and constraint in predicting adolescent solitary drinking.

The current study used a structural equation modeling (SEM) approach to examine correlates of adolescent solitary drinking after controlling for alcohol quantity/frequency. This path analytical strategy allowed for the simultaneous examination of personality influences (negative emotionality, constraint) on solitary drinking, and the ability to test mediation to determine whether drinking to cope with negative affect is a mechanism linking personality traits and solitary drinking. We hypothesized that higher levels of negative emotionality and lower levels of constraint would predict solitary drinking and that these relationships would be mediated by the ability to resist drinking in response to negative emotions. To show that the effects of personality on solitary drinking are mediated specifically by the ability to resist drinking during negative affect, and not by a general lack of coping ability, we also included a measure of general adaptive coping (i.e. an individual's overall ability to deal adaptively and effectively with the environment.)

\section{METHODS}

\section{Participants}

Participants were 761 adolescents aged $12-20$ years [ $46.1 \%$ female; mean age $=17.1$ years, standard deviation $(\mathrm{SD})=1.6$ years] recruited through the Pittsburgh Adolescent Alcohol 
Research Center. This sample includes participants from our prior study on adolescent solitary drinkers, $n=709$ [11]. Participants who were aged 12-18 years were recruited from clinical (67\%) and community (33\%) sources to represent a range of alcohol involvement: 507 clinical cases ( 207 females, 300 males) were recruited from psychiatric and addictions treatment settings and juvenile justice programs; 254 community cases (144 females, 110 males) were recruited through the use of telephone sampling and advertisements. Exclusion criteria included psychosis, mental retardation and a history of serious neurological disturbance. Community cases were not excluded if they reported AUD symptoms at recruitment. The sample was $81.9 \%$ Caucasian, $17.5 \%$ African American and fewer than 1\% other race/ethnic backgrounds.

\section{Procedures}

Participants were assessed initially between the ages of 12 and 18 years. Measures included life-time alcohol and drug use, substance use disorders and other psychopathology, personality and other variables. Similar measures were used for 1-, 3- and 5-year follow-up assessments, which covered the interval since the last completed assessment. Data for these analyses were drawn from the baseline assessment if the teen was a regular drinker (i.e. drinking at least once per month for at least 6 months) and was asked about solitary versus social drinking. Most (73.5\%) of the cases included in the analysis used baseline data. Otherwise, data were used from the first follow-up assessment (up to age 20; that is, prior to the legal drinking age in the United States) at which they reported being a regular drinker (10.9\% of the sample at 1-year follow-up; $10.0 \%$ of the sample at 3-year follow-up; $5.7 \%$ of the sample at 5-year follow-up), such that each case provided cross-sectional data for analyses. Participants received compensation for completing each assessment. The study was approved by the University of Pittsburgh Institutional Review Board (IRB). Written informed consent was obtained from a parent for the minor's participation, and the adolescent provided assent (or consent if age $>18$ ).

\section{Measures}

Demographics-The baseline assessment collected data on age, gender, ethnicity and socio-economic status (SES), as indicated by the Hollingshead Two-Factor Index [32].

Alcohol use and solitary drinking-Alcohol consumption and solitary versus socialonly drinking in the past year were measured by the Lifetime Drinking History method [33], which has shown good reliability and validity with adolescents [34]. Participants reported alcohol use frequency, average quantity of alcohol consumed per occasion (in standard drinks) and percentage of time that their drinking occurred while alone versus with others (on a $0-100 \%$ scale) in the past year [11].

\section{Personality factors}

Negative emotionality-Negative emotionality (NEM) was indexed by the stress reaction, alienation, and aggression subscales of the Multidimensional Personality Questionnaire (MPQ) [35]. These three scales comprise the higher-order factor of negative emotional temperament [35], which is a widely used measure of trait negative affectivity. High scores on the MPQ negative emotional temperament factor reflect a proneness to 
experience anxiety, anger and related emotional and behavioral negative engagement [35]. The MPQ has been shown to be a reliable and valid measure for use with adolescents and young adults [36,37].

Constraint-Constraint (CON) was defined by the three facets of the MPQ that comprise the higher order constraint factor (i.e. harm avoidance, traditionalism, and control) [35]. Constraint generally refers to the ability to inhibit one's behavioral impulses, and low constraint on the MPQ indicates the proneness to act on impulses and take risks.

\section{Coping-related variables}

General coping ability-The Constructive Thinking Inventory (CTI) [38,39] S. Epstein, unpublished manuscript, 1992 assesses constructive thinking or general coping ability (GENCOPE), defined as dealing adaptively and effectively with the environment. Items (e.g. 'When I have a lot of important things to take care of, I make a plan and stick to it') used five response options: 'definitely false', 'mostly false', 'undecided', 'mostly true' and 'definitely true'. This newer 108-item CTI provides more reliable scores on the original scales [38] and has good construct validity, as indicated by the relations of its scales with a wide variety of criteria of success in living in adults [40,41] and adolescents [42]. The CTI yields the Global Constructive Thinking scale (30 items drawn from each of the six domain scales, $a=0.90$ ), represented as the variable GENCOPE [38].

Ability to resist alcohol during negative affective states-The ability to resist drinking alcohol during negative affective states (ALCRES) was indexed with the Situational Confidence Questionnaire-Alcohol (SCQA) [43,44]. Participants indicated their confidence to resist heavy alcohol consumption in specific situations (e.g. 'If other people didn't seem to like me') from 0 to $100 \%$ (in increments of 20\%). The 39 items of the SCQA are drawn from the Inventory of Drinking Situations [44], the latter of which has been shown to be a reliable and valid measure for use with adolescents [45]. Four subscales were combined to create a factor indexing the ability to resist alcohol during negative affective states (ALCRES) — unpleasant emotions (UE), urges or temptations (UT), social tension (ST) and social problems at work/school (SP). Principal-axis factor analyses revealed a onefactor solution that accounted for $83.77 \%$ of the variance (factor loadings: UE $=0.95$, UT $=$ $0.84, \mathrm{ST}=0.96, \mathrm{SP}=0.90$ ).

\section{DATA ANALYSIS}

SEM was run with Mplus version 7 [46]. Latent factors were estimated in the measurement model for NEM, CON, GENCOPE and ALCRES constructs. Across measurement and path models, all variables, including the outcome ALONE, were conditioned on the following observed variables: gender, age, ethnicity, SES and past year alcohol consumption (quantity/ frequency). Path models were also estimated with recruitment source (clinical/community) entered as a covariate, and findings resulted in the same conclusions. Due to the extreme sensitivity of the $\chi^{2}$ test to negligible sources of ill fit in large samples, we follow convention and rely upon multiple alternative fit indices to evaluate model fit [47]. Because our structural models ultimately included a binary outcome (ALONE), we used a robust weighted least squares estimator (WLSMV) in all models. The WLSMV estimator option 
uses a pairwise present approach to missing data, which was supported given that Little's $\chi^{2}$ test indicated data were missing completely at random.

\section{RESULTS}

Of the 761 participants, $162(21.3 \%)$ reported drinking alone at least once in the past year and $599(78.7 \%)$ reported drinking only in social settings in the past year. The percentage of solitary drinkers reported here differs from our prior paper due to a difference in the assessment time-frame across the two studies. In our prior paper, we calculated the percentage of teens who reported any solitary drinking during the ages of 12-18 years. Here, we assessed solitary drinking during the prior year only, so that each case provided crosssectional data of solitary drinking and other relevant data (e.g. personality assessments). Of those who reported any solitary drinking in the past year, the mean percentage of time spent drinking in a solitary situation was $23.9 \%$ ( $\mathrm{SD}=24.4$; range $=1-100 \%)$. As the distribution of solitary drinking was highly skewed and contained many zero values, a binary variable was created to capture the distinction between individuals who reported any versus no solitary drinking during the past year [11].

Table 1 shows participant characteristics and descriptive statistics for the observed variables across solitary and social-only drinkers. Solitary drinkers consumed alcohol at a higher quantity and frequency, were more likely to be male, to be recruited from clinical settings and to be younger than adolescents who only drank in social settings. Solitary, compared to social-only, drinkers reported more negative affect, less constraint, less general coping ability and less ability to resist alcohol during negative emotions.

\section{Measurement model}

We first constructed a measurement model to determine if study variables were associated independently with the binary outcome variable of solitary drinking (ALONE). A measurement model with four latent factors corresponding to study constructs evidenced good fit to the data $\left[\chi_{(45)}^{2}=122.63, P<0.001\right.$; root mean square error of approximation $($ RMSEA $)=0.048,90 \%$ confidence interval $(\mathrm{CI})=0.038-0.058$; comparative fit index $(C F I)=0.96]$ (see Fig. 1). For all latent variables, all factor loadings were significant. Due to a very large modification index and conceptual overlap (e.g. aggression and lack of constraint are observed in externalizing psychopathology) [30,31], we allowed the MPQ AG scale to cross-load on CON. As seen in Fig. 1, after controlling for demographic and alcohol consumption variables (as described in Data analysis), three of the four latent variables were related significantly to ALONE. The relationship between NEM and ALONE was marginally significant $(P=0.06)$. [Note: Supporting information, Table 1 shows regression pathways between observed variables and drinking quantity/frequency.] To determine whether solitary drinking was related to the ability to resist alcohol during negative affective states specifically, and not a more general ability to resist alcohol, we ran logistic regression analyses predicting solitary drinking from all others scales of the Situational Confidence Questionnaire (i.e. pleasant emotions, positive social situations, testing personal control and physical discomfort). None of the other scales predicted solitary drinking $(P \mathrm{~s}>0.15)$. 


\section{Path model of personality, ability to resist alcohol during negative affective states, general coping and solitary drinking}

We then sought to test a model in which coping variables (GENCOPE and ALCRES) mediated the relationship between personality constructs (NEM and CON) and solitary drinking status (ALONE). We first estimated a nested structural model in which latent GENCOPE and ALCRES were each regressed on NEM and CON, and ALONE was regressed on all four latent variables. Both coping variables were predicted significantly by both personality variables in the expected directions. Specifically, higher NEM predicted lower GENCOPE $[\beta=0-0.61$, standard error $(\mathrm{SE})=0.06, P<0.001]$ and lower ALCRES $(\beta$ $=-0.27, \mathrm{SE}=0.05, P<0.001)$ and higher $\mathrm{CON}$ predicted higher GENCOPE $(\beta=0.11, \mathrm{SE}=$ $0.06, P=0.003)$ and higher ALCRES $(\beta=0.17, \mathrm{SE}=0.06, P=0.001)$. Solitary drinking variation (solitary drinkers coded as 1 and social-only drinkers coded as 0 ) was significantly and directly predicted by CON $(\mathrm{OR}=0.82 ; b=-0.19, \mathrm{SE}=0.08, P=0.014)$ and ALCRES $(\mathrm{OR}=0.86 ; b=-0.14, \mathrm{SE}=0.05, P=0.014)$. In contrast, solitary drinking was not associated directly with NEM (OR $=0.96 ; b=-0.04, \mathrm{SE}=0.09, P=0.665)$ (that is, only the meditational effect through ALCRES was significant). The link between GENCOPE and ALONE was no longer significant $(\mathrm{OR}=0.94 ; b=-0.06, \mathrm{SE}=0.05, P=0.211)$ after accounting for the influence of NEM, CON and ALCRES.

Figure 2 shows the final mediational model. As displayed, we removed the non-significant direct pathway between NEM and ALONE, leaving only the significant mediational effect through ALCRES. We also removed the non-significant path from GENCOPE to ALONE.

This final model had good fit $\left(\chi_{(48)}^{2}=125.54, P<0.001\right.$; RMSEA $=0.046,90 \% \mathrm{CI}=0.037-$ 0.056; CFI $=0.95$ ) and a $\chi^{2}$ difference test (DIFF option in Mplus) indicated that this mediational model did not result in a significant degradation in model fit from the baseline measurement model $\left(\Delta \chi_{(3)}^{2}=2.90, \mathrm{P}=0.41\right)$. The relationship between NEM and ALONE was fully mediated by ALCRES $(b=0.05, P=.01)$, whereas CON exerted a direct effect on ALONE (OR $=0.79, b=-0.23, P<.01)$ as well as an indirect effect through ALCRES $(b=$ $-0.03, P=.02)$. The indirect effects. To test for age effects, we split the sample at the median age (17 years) and conducted a multi-group SEM on the final path model. $\chi^{2}$ difference tests indicated that constraining parameters across groups did not result in a significant degradation in fit, suggesting that age was not a moderator. We thank an anonymous reviewer for requesting this analysis.

\section{DISCUSSION}

Analyses revealed specific pathways from personality traits to coping responses that inform our basic understanding of motivations for solitary drinking. As hypothesized, the associations of solitary drinking with negative emotionality and constraint were both mediated by the ability to resist drinking during negative affect. Contrary to prediction, however, trait negative emotionality was not associated directly with solitary drinking after accounting for the ability to resist drinking during negative emotions. This finding is important, because it suggests that it is not simply experiencing distress that relates to drinking alone (as found in prior studies), but rather the inability to resist drinking during such distress that increases the likelihood of engaging in this risky drinking pattern. These 
results lend credence to the self-medication hypothesis of adolescent solitary drinking $[11,21]$.

Results also showed that lower trait constraint directly predicted solitary drinking and exerted an indirect effect on drinking alone through the ability to resist drinking during negative emotional states. The former result is consistent with prior research linking solitary drinking to deviant behavior [12] and highlights the importance of dis-inhibition in predicting adolescents' propensity to drink alone. The latter finding extends previous work by suggesting that negative affect coping might be an important mechanism linking impulsivity to solitary drinking. Finally, the link between general coping ability and solitary drinking was no longer significant after accounting for the influence of personality factors and the ability to resist alcohol during negative affect states. This result indicates that the ability to resist alcohol when experiencing negative affect specifically, rather than a generally constructive thinking style, seems to be a particularly important mechanism linking trait negative emotionality and constraint with adolescent solitary drinking.

The present study adds to the literature on the correlates of solitary drinking by using an SEM approach to simultaneously examine the influence of negative emotionality, constraint, general coping ability and the ability to resist drinking alcohol during negative emotional states on likelihood of solitary drinking. This analytical strategy allowed us to provide separate estimates of relations among latent constructs and their indicators (in the measurement model), as well as to examine the relations among constructs (in the path model). Consequently, we were able to both assess the psychometric properties of measures and estimate relations among constructs after correcting for biases attributable to random error and construct-irrelevant variance [48], a clear extension of prior work in this area. Importantly, we controlled for alcohol consumption variables in our model, which allowed us to examine associations with solitary drinking after partialing out variance accounted for by general drinking. The current findings clarify and extend previous research by highlighting specific pathways to solitary drinking — higher levels of impulsivity and a decreased ability to resist alcohol consumption during negative emotional states-after accounting for general alcohol involvement.

One limitation is that these analyses were based on cross-sectional data, which does not permit causal conclusions about the predictive or temporal relationships among personality factors, coping-related variables and solitary drinking status (e.g. [49]). However, our model is consistent with longitudinal research supporting a unidirectional, rather than reciprocal, association whereby individual differences in personality predict subsequent drinking outcomes [50,51]. None the less, additional research is needed to predict longitudinally the emergence of solitary drinking among adolescents who have not yet begun to drink, especially as prospective studies have con-firmed that adolescent solitary drinking predicts alcohol problems in young adulthood [11,12]. Also, the generaliz-ability of these results may be limited, although inclusion of adolescents from clinical and community sources provided a range in severity of alcohol involvement. Furthermore, we assessed drinking to cope by asking about the ability to resist drinking alcohol during negative emotional states. Although these constructs are conceptually similar, it will be important to test our model using more direct measures of drinking motives (e.g. [26]). Finally, we used a binary 
variable of solitary drinking in our analyses (there are limitations with dichotomizing a continuous variable) and, although our model achieved good fit to the data, another limitation is that an alternative model was not tested.

Solitary drinking in adolescence prospectively predicts alcohol problems in young adulthood above and beyond other established risk factors for alcohol problems [11,12], and thus it is important to understand factors that explain this risky behavior. Our results suggest that ability to resist drinking during negative affective states is a mechanism that links trait negative emotionality and constraint with drinking alone. These findings are consistent with a self-medication hypothesis of adolescent solitary drinking [11,21]. Importantly, as drinking to cope seems to be a reliable indicator of solitary drinking, results suggest the potential utility of interventions that help adolescents (particularly those who report solitary drinking) to resist alcohol use in situations involving negative affect.

\section{Acknowledgements}

This paper was supported by the following US Public Health Service Grants: R01AA016482 (DBC), U01AA021690 (DBC), R01AA021721 (CSM), R01AA13397 (CSM), K24AA020840 (CSM) and K02AA018195 (TC).

\section{References}

1. Johnston, LD.; O'Malley, PM.; Bachman, JG.; Schulenberg, JE. Monitoring the Future: National Results on Adolescent Drug Use. Overview of Key Findings, 2005. National Institutes of Health, US Department of Health and Human Services; Bethesda, MD: 2006.

2. Mann LM, Chassin L, Sher KJ. Alcohol expectancies and the risk for alcoholism. J Consult Clin Psychol. 1987; 55:411-7. [PubMed: 3597957]

3. Engels RCME, Knibbe RA, Drop MJ. Why do late adolescents drink at home? A study on psychological well-being, social integration and drinking context. Addict Res Theory. 1999; 7:3146.

4. Allen JP, Porter MR, McFarland FC, Marsh P, McElhaney KB. The two faces of adolescents' success with peers: adolescent popularity, social adaptation, and deviant behavior. Child Dev. 2005; 76:747-60. [PubMed: 15892790]

5. Jessor R. Risk behavior in adolescence: a psychosocial framework for understanding and action. J Adolesc Health. 1991; 12:597-605. [PubMed: 1799569]

6. Leifman H, Kühlhorn E, Allebeck P, Andréasson S, Romelsjö A. Abstinence in late adolescenceantecedents to and covariates of a sober lifestyle and its consequences. Soc Sci Med. 1995; 41:11321. [PubMed: 7667664]

7. Bourgault C, Demers A. Solitary drinking: a risk factor for alcohol-related problems? Addiction. 1997; 92:303-12. [PubMed: 9219392]

8. Demers A, Bourgault C. Changing society, changing drinking: solitary drinking as a nonpathological behaviour. Addiction. 1996; 91:1505-16. [PubMed: 8917918]

9. Cahalan, D.; Room, R. Problem Drinking Among American Men. Rutgers Center of Alcohol Studies; Piscataway, NJ: 1974.

10. Johnston, LD.; Bachman, JG.; O'Malley, PM. Monitoring the Future: Questionnaire Responses From The Nation's High School Seniors, 2011. University of Michigan, Institute for Social Research; Ann Arbor, MI: 2013.

11. Creswell KG, Chung T, Clark DB, Martin CS. Solitary alcohol use in teens is associated with drinking in response to negative affect and predicts alcohol problems in young adulthood. Clin Psychol Sci. 2014; 2:602-10. [PubMed: 25977842] 
12. Tucker JS, Ellickson PL, Collins RL, Klein DJ. Does solitary substance use increase adolescents' risk for poor psychosocial and behavioral outcomes? A 9-year longitudinal study comparing solitary and social users. Psychol Addict Behav. 2006; 20:363-72. [PubMed: 17176171]

13. Belcher AM, Volkow ND, Moeller FG, Ferré S. Personality traits and vulnerability or resilience to substance use disorders. Trends Cogn Sci. 2014; 18:211-17. [PubMed: 24612993]

14. Crum RM, Green KM, Storr CL, Chan YF, Ialongo N, Stuard EA, et al. Depressed mood in childhood and subsequent alcohol use through adolescence and young adulthood. Arch Gen Psychiatry. 2008; 65:702-12. [PubMed: 18519828]

15. Kotov R, Gamez W, Schmidt F, Watson D. Linking 'big' personality traits to anxiety, depressive, and substance use disorders: a meta-analysis. Psychol Bull. 2010; 136:768-821. [PubMed: 20804236]

16. Sher KJ, Grekin ER, Williams NA. The development of alcohol use disorders. Annu Rev Clin Psychol. 2005; 1:493-523. [PubMed: 17716097]

17. Sihvola E, Rose RJ, Dick DM, Pulkkinen L, Marttunen M, Kaprio J. Early-onset depressive disorders predict the use of addictive substances in adolescence: a prospective study of adolescent Finnish twins. Addiction. 2008; 103:2045-53. [PubMed: 18855807]

18. Martin CS, Lynch KG, Pollock NK, Clark DB. Gender differences and similarities in the personality correlates of adolescent alcohol problems. Psychol Addict Behav. 2000; 14:121-33. [PubMed: 10860111]

19. Christiansen M, Vik PW, Jarchow A. College student heavy drinking in social contexts versus alone. Addict Behav. 2002; 27:393-404. [PubMed: 12118627]

20. Gonzalez VM, Skewes MC. Solitary heavy drinking, social relationships, and negative mood regulation in college drinkers. Addict Res Theory. 2013; 21:285-94.

21. Tomlinson KL, Brown SA. Self-medication or social learning? A comparison of models to predict early adolescent drinking. Addict Behav. 2012; 37:179-86. [PubMed: 22055793]

22. Gonzalez VM, Collins RL, Bradizza CM. Solitary and social heavy drinking, suicidal ideation, and drinking motives in underage college drinkers. Addict Behav. 2009; 34:993-9. [PubMed: 19556066]

23. Reese FL, Chassin L, Molina BSG. Alcohol expectancies in early adolescents: predicting drinking behavior from alcohol expectancies and parental alcoholism. J Stud Alcohol Drugs. 1994; 55:276.

24. Sher KJ, Trull TJ. Personality and disinhibitory psychopathology: alcoholism and antisocial personality disorder. J Abnorm Psychol. 1994; 103:92-102. [PubMed: 8040486]

25. Mohr CD, Armeli S, Tennen H, Carney MA, Affleck G, Hromi A. Daily interpersonal experiences, context, and alcohol consumption: crying in your beer and toasting good times. J Pers Soc Psychol. 2001; 80:489-500. [PubMed: 11300581]

26. Cooper LM. Motivations for alcohol use among adolescents: development and validation of a fourfactor model. Psychol Assess. 1994; 6:117-28.

27. Cooper LM, Frone MR, Russell M, Mudar P. Drinking to regulate positive and negative emotions: a motivational model of alcohol use. J Pers Soc Psychol. 1995; 69:990-1005. [PubMed: 7473043]

28. Kuntsche E, Knibbe R, Gmel G, Engels R. Why do young people drink? A review of drinking motives. Clin Psychol Rev. 2005; 25:841-61. [PubMed: 16095785]

29. Sher, KJ.; Trull, TJ.; Bartholow, B.; Vieth, A. Psychological Theories of Drinking and Alcoholism. 2nd edn.. Plenum Press; New York: 1999. Personality and Alcoholism: Issues, Methods, and Etiological Processes.; p. 55-105.

30. Wright AGC, Krueger RF, Hobbs MJ, Markon KE, Eaton NR, Slade T. The structure of psychopathology: toward an expanded quantitative empirical model. J Abnorm Psychol. 2013; 122:281-94. [PubMed: 23067258]

31. Krueger RF, Markon KE, Patrick CJ, Benning SD, Kramer MD. Linking antisocial behavior, substance use, and personality: An integrative quantitative model of the adult externalizing spectrum. J Abnorm Psychol. 2007; 116:645-66. [PubMed: 18020714]

32. Hollingshead, AB. Two-Factor Index of Social Status. Yale University; New Haven, CT: 1975.

33. Skinner HA, Sheu WJ. Reliability of alcohol use indices; the lifetime drinking history and the MAST. J Stud Alcohol Drugs. 1982; 43:1157. 
34. Clark DB, Pollock NK, Mezzich A, Cornelius J, Martin C. Diachronic substance use assessment and the emergence of substance use disorders. J Child Adolesc Subst Abuse. 2001; 10:13-22.

35. Tellegen, A.; Waller, NG. SAGE Handbook of Personality Theory and Assessment: Personality Measurement and Testing. Vol. 1. JAI Press; Greenwich, CT: 1994. Exploring Personality Through Test Construction: Development of the Multidimensional Personality Questionnaire..

36. Krueger RF. Personality traits in late adolescence predict mental disorders in early adulthood: a prospective-epidemiological study. J Pers. 1999; 67:39-65. [PubMed: 10030020]

37. McGue M, Bacon S, Lykken D. Personality stability and change in early adulthood: a behavioral genetic analysis. Dev Psychol. 1993; 29:96-109.

38. Epstein S. Coping ability, negative self-evaluation, and over-generalization: experiment and theory. J Pers Soc Psychol. 1992; 62:826-36. [PubMed: 1593422]

39. Spirrison C, Gordy C. Nonintellective intelligence and personality: variance shared by the Constructive Thinking Inventory and the Meyers-Briggs Type Indicator. J Pers Assess. 62:35263. n.d. [PubMed: 8189343]

40. Epstein S, Katz L. Coping ability, stress, productive load, and symptoms. J Pers Soc Psychol. 1992; 62:813-25. [PubMed: 1593421]

41. Epstein, S. Constructive thinking and mental and physical well-being.. In: Montada, L.; Filipp, SH.; Lerner, M., editors. Life Crises and Experiences of Loss in Adulthood. Erlbaum; Hillsdale, NJ: 1992. p. 385-409.

42. Ammerman RT, Lynch KG, Donovan JE, Martin CS, Maisto SA. Constructive thinking in adolescents with substance use disorders. Psychol Addict Behav. 2001; 15:89-96. [PubMed: 11419235]

43. Annis, H.; Davis, CS. Self-efficacy and the prevention of alcoholic relapse: Initial findings from a treatment trial.. In: Baker, TB.; Cannon, DS., editors. Assessment and Treatment of Addictive Disorders. Praeger Publishers; New York, NY/UK: 1988. p. 88-112.

44. Annis, H.; Graham, JM.; Davis, CS. Inventory of Drinking Situations (IDS): User's Guide. Addiction Research Foundation; Toronto: 1987.

45. Parra GR, Martin CS, Clark DB. The drinking situations of adolescents treated for alcohol use disorders: a psychometric and alcohol-related outcomes investigation. Addict Behav. 2005; 30:1725-36. [PubMed: 16111833]

46. Muthén, LK.; Muthén, BO. Mplus User's Guide. 7th edn.. Muthén and Muthén; Los Angeles, CA: 2012.

47. Brown, TA. Confirmatory Factor Analysis for Applied Research. Guilford Press; New York, NY: 2006.

48. Tomarken AJ, Waller NG. Structural equation modeling: strengths, limitations, and misconceptions. Annu Rev Clin Psychol. 2005; 1:31-65. [PubMed: 17716081]

49. Gonzalez VM. Association of solitary binge drinking and suicidal behavior among emerging adult college students. Psychol Addict Behav. 2012; 26:609-14. [PubMed: 22288976]

50. Morey LC, Hopwood CJ, Markowitz JC, Gunderson JG, Grilo CM, McGlashan TH, et al. Comparison of alternative models for personality disorders, II: 6-, 8- and 10-year follow-up. Psychol Med. 2012; 42:1705-13. [PubMed: 22132840]

51. Luyten P, Blatt SJ. Interpersonal relatedness and self-definition in normal and disrupted personality development: Retrospect and prospect. Am Psychol. 2013; 68:172-83. [PubMed: 23586492] 


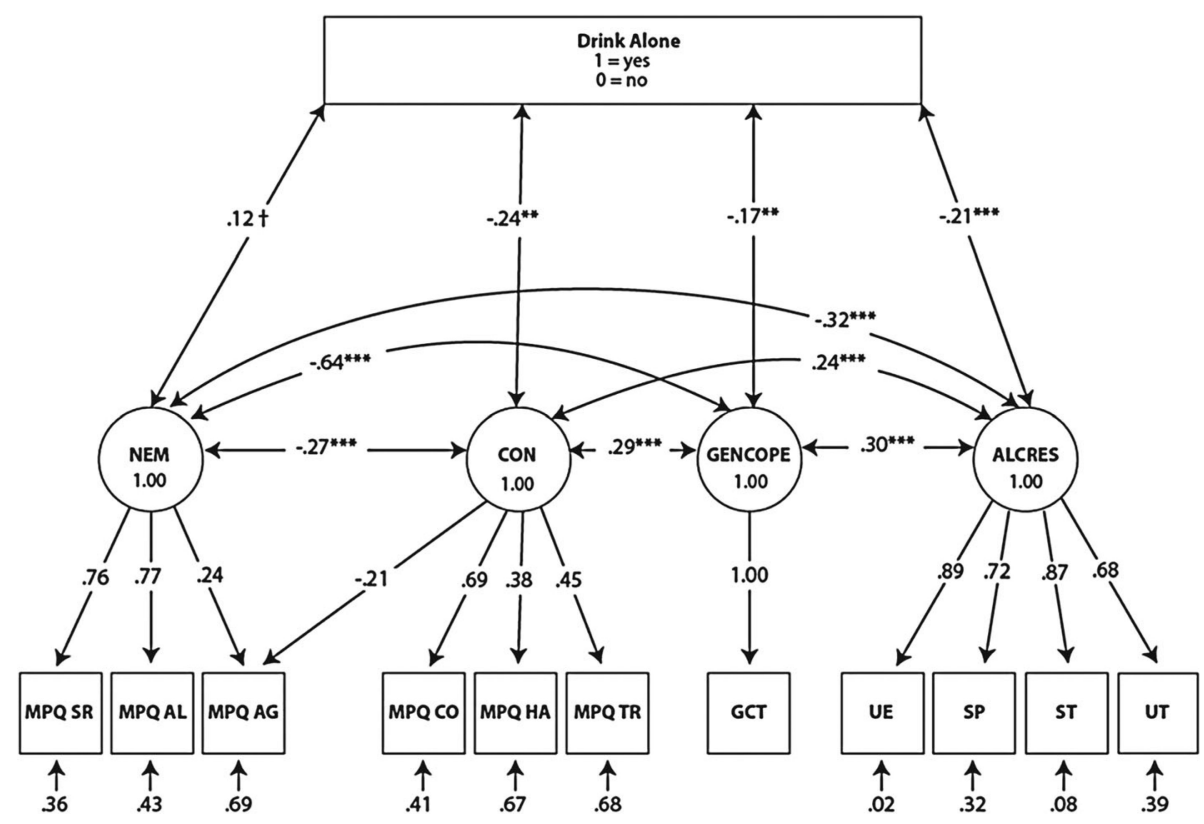

Figure 1.

Measurement model. $\dagger P=0.06$; $* * P<0.01 ; * * * P<0.001$. All factor loadings were significant at $P<0.001$. All path coefficients are standardized. The following covariates were included: gender, age, ethnicity, socio-economic status (SES) and past year alcohol consumption (quantity/frequency). NEM = MPQ negative emotionality; CON = MPQ constraint; GENCOPE = general coping ability; ALCRES = ability to resist drinking alcohol during negative affect; MPQ SR = PQ stress reaction; MPQ AL = MPQ alienation; MPQ $\mathrm{AG}=\mathrm{MPQ}$ aggression; MPQ CO = MPQ control; MPQ HA = MPQ harm avoidance; MPQ $\mathrm{TR}=$ MPQ traditionalism; GCT = global constructive thinking; UE = unpleasant emotions; $\mathrm{SP}=$ social problems at school/work; $\mathrm{ST}=$ social tension; $\mathrm{UT}=$ urges and temptations 


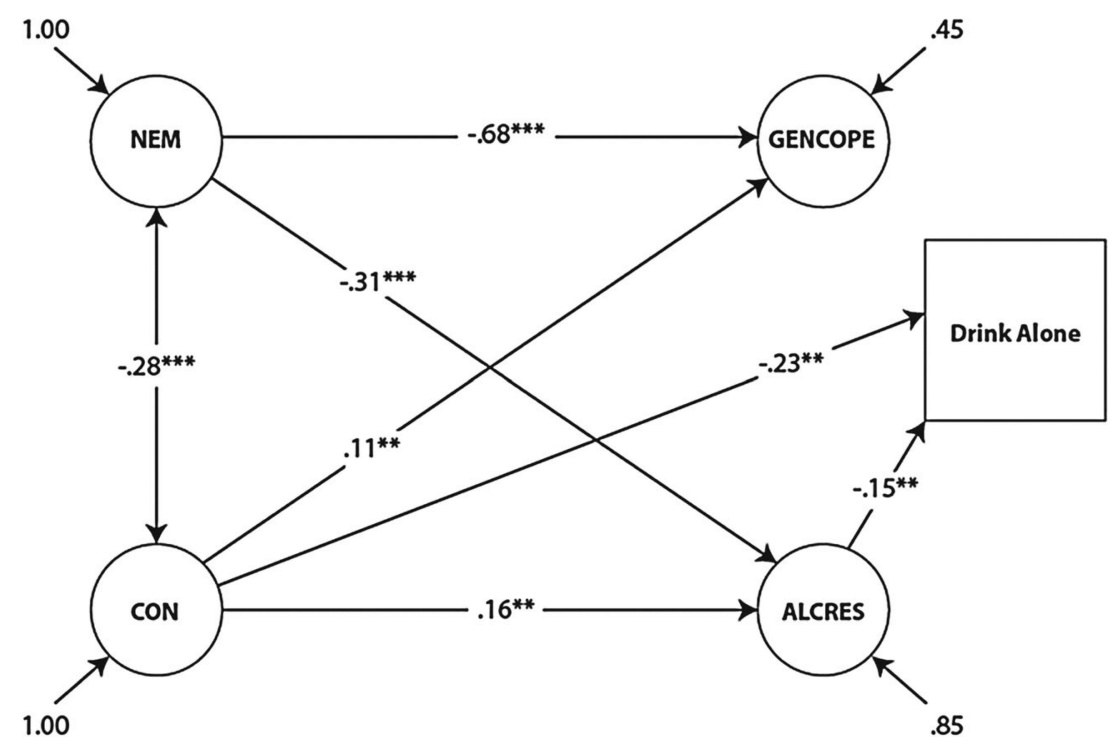

Figure 2.

Path model of personality, ability to resist alcohol during negative affect states, general coping, and solitary drinking. $* * P<0.01 ; * * * P<0.001$. Path coefficients between continuous variables are standardized; path coefficients for the binary variable of drink alone are unstandardized. All variables, including drink alone, were conditioned on the following covariates: gender, age, ethnicity, socio-economic status (SES) and past year alcohol consumption (quantity/frequency). $\mathrm{NEM}=\mathrm{MPQ}$ negative emotionality; $\mathrm{CON}=$ MPQ constraint; GENCOPE = general coping ability; ALCRES = ability to resist drinking alcohol during negative affect. Drink alone $(1=$ yes, $0=$ no $)$ 
Table 1

Participant characteristics and descriptive statistics for observed variables across adolescent solitary and social-only drinkers.

\begin{tabular}{|c|c|c|c|c|c|c|c|}
\hline & \multicolumn{2}{|c|}{$\underline{\text { Solitary }(n=162)}$} & \multicolumn{2}{|c|}{$\underline{\text { Social-only }(n=599)}$} & \multirow[b]{2}{*}{$\chi^{2}$} & \multirow[b]{2}{*}{$\boldsymbol{F}$} & \multirow[b]{2}{*}{$p$} \\
\hline & $n / m e a n$ & $\% / S D$ & $n / m e a n$ & $\% / S D$ & & & \\
\hline Age & 16.9 & 1.59 & 17.2 & 1.61 & & 5.07 & 0.025 \\
\hline \multicolumn{8}{|l|}{ Gender } \\
\hline Male & 103 & 63.5 & 307 & 51.3 & 7.79 & & 0.005 \\
\hline Female & 59 & 36.5 & 292 & 48.7 & & & \\
\hline \multicolumn{8}{|l|}{ Ethnicity } \\
\hline Caucasian & 134 & 83.2 & 489 & 82.2 & 0.09 & & 0.757 \\
\hline African American ${ }^{a}$ & 27 & 16.8 & 106 & 17.8 & & & \\
\hline SES & 38.8 & 12.7 & 38.1 & 12.9 & & 0.31 & 0.576 \\
\hline \multicolumn{8}{|l|}{ Recruitment source } \\
\hline Clinical & 135 & 83.3 & 372 & 62.1 & 25.85 & & $<0.001$ \\
\hline Community & 27 & 16.7 & 227 & 37.9 & & & \\
\hline \multicolumn{8}{|l|}{ Alcohol quantity/frequency } \\
\hline Number of drinks per drinking day (past year) & 9.9 & 6.7 & 5.5 & 5.2 & & 81.6 & $<0.001$ \\
\hline Drinking days per month (past year) & 10.3 & 7.9 & 4.0 & 5.4 & & 140.9 & $<0.001$ \\
\hline \multicolumn{8}{|l|}{ Negative emotionality } \\
\hline MPQ-stress reaction & 14.9 & 6.1 & 13.0 & 6.4 & & 9.8 & $<0.01$ \\
\hline MPQ-alienation & 9.7 & 5.0 & 8.3 & 5.3 & & 8.2 & $<0.01$ \\
\hline MPQ-aggression & 12.5 & 4.5 & 10.9 & 5.0 & & 11.5 & $<0.01$ \\
\hline \multicolumn{8}{|l|}{ Constraint } \\
\hline MPQ-harm avoidance & 13.8 & 5.6 & 15.9 & 6.0 & & 13.9 & $<0.001$ \\
\hline MPQ-traditionalism & 13.0 & 4.5 & 14.8 & 4.5 & & 18.1 & $<0.001$ \\
\hline MPQ-control & 9.6 & 4.7 & 11.6 & 4.8 & & 20.3 & $<0.001$ \\
\hline \multicolumn{8}{|l|}{ General coping ability } \\
\hline CTI-global & 90.6 & 16.5 & 97.0 & 16.5 & & 18.1 & $<0.001$ \\
\hline \multicolumn{8}{|l|}{ Alcohol resistance } \\
\hline SCQA-unpleasant emotions & 58.4 & 29.3 & 75.6 & 26.6 & & 47.9 & $<0.001$ \\
\hline SCQA-urges/temptations & 51.6 & 28.8 & 68.4 & 28.7 & & 41.1 & $<0.001$ \\
\hline SCQA-social tension & 63.3 & 29.9 & 77.6 & 25.9 & & 33.7 & $<0.001$ \\
\hline SCQA-social problems & 69.5 & 29.3 & 80.0 & 27.1 & & 17.3 & $<0.001$ \\
\hline
\end{tabular}

${ }^{a}$ Fewer than $1 \%$ of the sample identified their ethnicity as 'other' $(n=4)$, and these individuals were not included in this analysis. Sample sizes range from 672 to 759 due to missing data for some questionnaires. SES = socio-economic status; MPQ = Multidimensional Personality Questionnaire; CTI = Constructive Thinking Inventory; SCQA=Situational Confidence Questionnaire-Alcohol; SD = standard deviation. 